\title{
O OfícIO dO hISTORIAdor ORAL: A VISÃo ItALIANA
}

Msc. Ricardo Santhiago'

Caselatto, Alessandro (org.). Il microfono rovesciato: 10 variazioni sulla storia orale. Treviso: Istresco, 2007.

Os nomes de Alessandro Portelli e Luisa Passerini estampados, entre outros, na capa de Il microfono rovesciato: 10 variazioni sulla storia orale não devem enganar. O simpático livro organizado pelo historiador Alessandro Casellato, da Università Ca'Foscari de Veneza, tem propostas e resultados que ultrapassam em muito as tendências intelectuais conhecidas internacionalmente graças ao trabalho de impacto exercido pelos dois autores mais conhecidos da história oral italiana, freqüentemente considerada uma das mais avançadas e influentes do mundo. Diferindo de balanços de experiência de grupo, de textos de recenseamento histórico e de esforços de divulgação de coletâneas e perfis institucionais, a obra publicada pelo Istresco - Istituto per la storia della Resistenza tem interesse geral.

Trata-se de um conjunto de dez entrevistas com intelectuais italianos que tiveram a história oral no horizonte de suas preocupações e práticas. Ao longo de 140 páginas, que incluem também uma introdução concisa, mas estimulante, da lavra de Casellato, é possível conhecer mais e melhor as linhas e feições da história oral italiana: suas condições de surgimento, seus precursores, seus campos de atuação, suas especificidades, seus diálogos disciplinares, seus autores principais. Num momento em que as histórias orais ao redor do mundo começam a "se" pensar historicamente, o livro sugere o alcance e o aspecto do que seria uma "história oral da história oral".

Em confronto com dois conhecidos textos que buscaram estabelecer uma avaliação crítica (não-oral) da história oral italiana - Le origini e il presente: Fonti orali e ricerca storica in Italia, de Cesare Bermani, e Italian Oral History: Roots of a paradox, de Alessandro Portelli -, os testemunhos se fortalecem como depositórios daquilo que estas análises não abrangem. O ofício do

\footnotetext{
I Jornalista graduado pela PUC-SP, especialista em Jornalismo Científico pela Unicamp, mestre e doutorando em História Social pela Universidade de São Paulo. Pesquisador do GEPHOM - Grupo de Estudo e Pesquisa em História Oral e Memória (EACH-USP), do Núcleo de Estudos em História da Cultura Intelectual e do MusiMid - Centro de Estudos em Música e Mídia. E-mail para contato: rsanthiago@usp.br.
} 
historiador oral, os percursos pessoais que conduzem ao trabalho de campo, as dificuldades cotidianas e o cruzamento de vocações e aptidões são, portanto, alguns dos motes centrais que perpassam os depoimentos.

De certo modo, os títulos das entrevistas - pequenas sentenças extraídas do corpo dos textos - dimensionam este encaminhamento; por isso, vale a pena arrolá-los: "E estes foram mais ou menos os começos" (Cesare Bermani); "As perguntas devem ser feitas a si mesmas" (Manlio Calegari); "Trazer à tona as memórias” (Luisa Passerini); “Aprendi como os artesãos: roubando com os olhos” (Alessandro Portelli); "Não são apenas palavras” (Tullio Telmon); "Um pouco de amor pela história dos outros” (Gabriella Gribaudi); “Saí andando de porta em porta” (Daniela Perco); “A história oral era uma blasfêmia” (Marco Fincardi); "Fugir do assunto” (Antonio Canovi); “Não sou capaz de fingir” (Marco Paolini).

A última, na verdade, é uma não-entrevista não-feita por Elisa Geremia com o ator, diretor e dramaturgo Marco Paolini, que utiliza a fonte oral em diversas etapas de seu trabalho artístico: na pesquisa que precede a escritura, no trabalho de preparação de atores, nas soluções para a encenação. Como não conseguiu agendar uma entrevista com o artista, a pesquisadora decidiu preparar um texto "no qual a informação e a invenção se fundem, como sempre ocorreu nas fontes orais” (p. 124), e que resulta atraente tanto pelos seus conteúdos quanto pela apresentação formal, que aparenta advir da oralidade.

Os outros nove textos, de entrevistas efetivamente realizadas, constituem um painel amplo que evidencia de imediato a acepção extensa de história oral na Itália, onde as fontes têm utilidade não apenas histórica, mas antropológica, sociológica, literária e mesmo dialetológica. Para além das discussões estatutárias que buscam defini-la como técnica, metodologia ou disciplina, tem-se a história oral como campo de interesse para onde podem convergir profissionais de diferentes áreas, portando alguns traços suficientemente reconhecíveis.

Em forma ou conteúdo, os depoimentos são marcados pela diversidade. Alguns têm organização cronológica; outros, temática. As perguntas, presentes em certas entrevistas, se tornam temas ou são suprimidas nas demais - e os autores ora o justificam, ora não, nos curtíssimos perfis de abertura. A regularidade está no fato de que cada texto resulta em uma breve história de vida trançada com a experiência pessoal de pesquisa em história oral.

Para o leitor estrangeiro, Il microfono rovesciato desfaz alegoricamente uma série de suposições sobre o lugar da história oral na cultural intelectual italiana. Ao declarar que conheceu Alessandro Portelli em um congresso internacional em Amsterdam, Luisa Passerini dá pistas de um estado de desarticulação que só a partir de 2006 vem sendo revisto graças à fundação da AISO -Associazione Italiana di Storia Orale. Passerini relata ainda sua atuação na fase heróica 
de estabelecimento e difusão das fontes orais, mas conta que por muito tempo voltou-se aos estudos sobre a identidade européia, retomando o trabalho com a oralidade apenas recentemente - o que contraria a idéia de que ela sempre esteve na linha de frente do suposto "movimento".

Com a intenção de perfazer três eixos - defender a viabilidade de se historiar a história oral; discutir a oportunidade de métodos formais no ensino de um "saber multiforme, indisciplinado (...), que cada um interpreta a seu modo" (p. 9); e refletir sobre a autoconsciência dos oralistas italianos -, o livro transforma-se numa obra de leitura agradável e intrigante, plena de descobertas. Da defesa da história do tempo presente, chega-se por exemplo ao entendimento de Manlio Calegari de que a oralidade pode auxiliar inclusive nos estudos de história de séculos passados, seja no uso de fontes de proveniência oral, como as judiciárias, seja por meio de entrevistas originais que evidenciem a permanência de antigos costumes.

Ainda que essencialmente diferenciados, os dez depoimentos exibem uma espécie de lençol subterrâneo que contamina condutas e aflui a convergências programáticas dimensionadas em idéias, nomes, objetos e objetivos comuns. Fala alto o reconhecimento e a reverência a pioneiros. É o caso de Nuto Revelli (19192004), autor da obra seminal Il mondo dei vinti: Testimonianze di vita contadina, de 1977; de Gianni Bosio (1923-1971), que dá nome ao famoso Circolo Gianni Bosio di Roma, centro de documentação e pesquisa de cultura e memória; e de Cesare Bermani (1937-), autor de inúmeras obras de referência, não por acaso o primeiro entrevistado do livro, "unanimemente considerado um dos pilares da história oral na Itália” (p. 13).

O reconhecimento ao saber dos pares também caracteriza o próprio processo de formação em história oral. A hipótese apresentada pelo organizador de que o oralista aprende com a experiência do outro, "copiando" para depois descobrir-se - fica clara em asserções como a de Daniela Perco: "pra mim foi um aprendizado exemplar ver Aurora Milillo fazer pesquisas de campo, ver o respeito que tinha na relação com os informantes (...). Aprendi mais com aquele período de pesquisa em Gennazzano, próximo a Roma, do que com horas e horas de aulas teóricas” (p. 92).

A historiadora Gabriela Gribaudi, por sua vez, afirma: "para mim, história oral não se aprende: só pode fazer história oral quem tem um pouco de amor pela história dos outros, um pouco de atenção pelas histórias em geral, quem se diverte ouvindo e tem um pouco de respeito pelos outros e por suas interpretações da vida e da história” (p. 85). Combinadas, a afetividade e a responsabilidade profissional indicam uma tendência geral: por mais que seja sistematizada em obras de cunho teórico, a prática de história oral requer um misto de aptidão e vocação. 
Não à toa, a epígrafe de Nuto Revelli estampada no início do livro - “cada um tem seu modo de entrevistar" - é retomada nos matizes das vidas narradas. Ainda que aspectos teóricos e metodológicos sejam repisados em fóruns acadêmicos, eles ainda aparecem como questões: a passagem do oral para o escrito; o arquivamento; a sensibilidade com mudanças geracionais; a adaptação de técnicas e temas; o contato com os informantes e as relações colaborativas estabelecidas em campo. Sem acompanhar respostas, as perguntas subjacentes às histórias de trabalho só são resolvidas no interior das próprias pesquisas e em conformidade com os propósitos e as convicções de cada profissional.

Por vezes, o trabalho do oralista, quando recoberto pelo engajamento político e social, chega a adquirir tons de missão. Diz Antonio Canovi: “a história oral, da forma como foi concebida e desenvolvida na Itália, era uma história de pertencimento: eu faço história oral porque pertenço a esta classe social, a esta cultura política, a este bairro. A oral history era um ponto de vista diferente” (p. 115). De fato, seja pela onipresença de 1968, pela ligação com os movimentos sociais e a luta anti-fascista ou pelo posicionamento partidário de seus autores, a carga política da história oral italiana é notável. Se, de um lado, isso contribuiu para o robustecimento de suas investidas, também culminou na situação apontada por Cesare Bermani: a dificuldade de alargamento temática e a reincidência de diversos estudos nos mesmos temas e períodos.

Trata-se de um dilema recente, em vias de resolução, e que levanta um dos eixos fundamentais para a reflexão "em" história oral e "sobre" história oral: o tempo. Fala-se, nas entrevistas, dos diversos momentos e movimentos deste campo; sabe-se, igualmente, que o próprio tempo abre um feixe de problemas para as relações entre entrevistadores e entrevistados, entre memória e história, entre fatos e relatos. Portanto, uma "história oral da história oral” já nasce dotada da consciência de seus conflitos e possíveis saídas. Gestada na Itália a partir da contribuição de quem, paradoxalmente, lida com histórias locais e tem atenção internacional, esta primeira experiência condensa tópicos comuns das "histórias orais" de muitos terrenos e, mostrando metanarrativamente as convergências entre vidas e percursos de oralistas, é em tudo motivadora. 